\title{
SUJEITOS DO ENSINAR: QUEM ENSINA, A QUEM SE ENSINA, QUEM É ENSINADO E QUEM APRENDE
}

\author{
Lilian Schwab Gelatti ${ }^{1}$, UFRGS, \\ liliangelatti@gmail.com
}

Resumo: Partindo do pressuposto que o ensinar consiste em uma prática coletiva na qual se intenciona que alguém aprenda, este artigo buscou identificar os sujeitos do ensinar - quem ensina, a quem se ensina, quem é ensinado e quem aprende - no Curso de Licenciatura em Pedagogia a distância da UFRGS. Com essa finalidade, apresentou a análise de dados e os resultados de uma pesquisa de pós-graduação de caráter metodológico qualitativo, respectivos a quatro de suas categorias analíticas. Uma parcela significativa de alunos, tutores, professores e coordenadores do Curso se identificou como sujeitos que ensinam, que ensinam a alguém do Curso, que são ensinados e que aprendem no Curso. Resulta que a afirmação ou a negação da ação de ensinar esteve presente entre as racionalidades que embasaram propostas e práticas pedagógicas dos sujeitos do Curso.

Palavras-chave: sujeitos, ensinar, aprender, modelo pedagógico, educação a distância.

\section{SUBJECTS OF THE TEACHING: WHO TEACHES, TO WHOM THEY TEACH, WHO IS TAUGHT AND WHO LEARNS}

\begin{abstract}
Assuming that the teaching consists of a group practice in which theyintend that someone learns, this article sought to identify the subjects of the teaching - who teaches, to whom they teach, who is taught and who learns - at the Graduation Course of Pedagogy by the distance of the UFRGS. With this purpose, it presented the data analysis and the results of a postgraduate research of a methodological qualitative nature, relating to four of its analytical categories. A significant portion of students, tutors, teachers and course coordinators identified themselves as subjects that teach, that teach someone in the course, that are taught and that learn in the course. The result is that the affirmation or negation of the teaching action was present among the rationales that supported pedagogical proposals and practices of the subjects of the course.
\end{abstract}

Keywords: subjects, teaching, learning, pedagogical model, distance education. 


\section{INTRODUÇÃO}

O ensinar é uma prática educacional intencional que implica ações e interações humanas. É, portanto, uma prática coletiva que envolve alguém que ensina e alguém que é ensinado ou, ainda, alguém a quem se ensina. Enquanto prática intencional, quem pratica o ensinar intenciona que alguém aprenda (Gelatti, 2012, p. 106). Tomando como base esse entendimento de ensinar articulado com o aprender, e se fundamentando em uma pesquisa de pós-graduação, o presente artigo se preocupa em identificar os sujeitos que praticam o ensinar e os para quem o ensinar é dirigido no âmbito de um curso de graduação de uma instituição pública brasileira de ensino superior, o Curso de Licenciatura em Pedagogia da Universidade Federal do Rio Grande do Sul, oferecido na modalidade a distância.

Para o cumprimento desta tarefa, este artigo se divide em sete seções, sendo que a primeira refere-se a esse texto introdutório e a segunda trata sobre a pesquisa mencionada, apresentando os principais procedimentos teórico-metodológicos adotados. A terceira seção investe esforços para identificar a quem se ensina; a quarta, quem é ensinado; a quinta, quem ensina; a sexta, quem ponderou que aprende no contexto de investigação considerado nessa pesquisa, sendo que essas seções abarcam a análise dos dados e os resultados da pesquisa. Na última seção retomam-se sinteticamente os resultados e apresentam-se as conclusões a respeito do objeto de estudo proposto.

\section{QUESTÕES DE PESQUISA}

Este artigo baseou-se na análise de quatro categorias da Tese de doutorado intitulada "Concepções e Práticas de Ensinar na Educação Superior a Distância”2 (Gelatti, 2012), defendida junto ao Programa de Pós-Graduação em Educação da Faculdade de Educação da Universidade Federal do Rio Grande do Sul (UFRGS). O Curso de Licenciatura em Pedagogia a distância (conhecido pela sigla PEAD) da Faculdade de Educação da UFRGS, realizado no período de agosto de 2006 a julho de 2011, consistiu no contexto de investigação dessa Tese, a qual se fundou em um estudo de caso caracterizado por uma abordagem de caráter qualitativo, ainda que tenha apresentado dados quantitativos para subsidiarem os seus dados qualitativos emergentes. Essas categorias de análise - quem ensina, quem é ensinado, a quem se ensina e quem aprende no Curso - foram construídas a partir da proposta teórico-metodológica da Tese, de dados coletados através da aplicação de um questionário, proposto no LimeSurvey ${ }^{3}$, e da realização de uma entrevista, abrangendo também registros dos sujeitos partícipes da pesquisa - alunos, tutores, professores e coordenadores do Curso - no ambiente virtual oficial do Curso (ROODA ${ }^{4}$ ).

Foram quatro as questões, de múltipla escolha com espaço para resposta livre e dissertativa no questionário (enviado a todos os integrantes do Curso) e semiestruturadas na entrevista (realizada com integrantes do Curso que responderam ao questionário, sendo selecionados de forma intencional), que possibilitaram dados mais específicos para a elaboração dessas categorias, as quais se apresentam a seguir: 
a) A quem você ensina no Curso? Essa questão foi respondida tanto por partícipes que consideraram que o ensinar estava incluído entre as ações que realizaram no Curso, na função que exerceram, quanto por partícipes que consideraram que foram ensinados por alguém no Curso e por aqueles que não o consideraram.

b) Você considera que seja ensinado por alguém no Curso? Essa questão foi respondida tanto por partícipes que consideraram que o ensinar estava incluído entre as ações que realizaram no Curso e por aqueles que não o consideraram, na função que exerceram, quanto por partícipes que consideraram que foram ensinados por alguém no Curso e por aqueles que não o consideraram.

c) Caso você considere que seja ensinado no Curso, quem lhe ensina? Essa questão foi respondida tanto por partícipes que consideraram que o ensinar estava incluído entre as ações que realizaram no Curso e por aqueles que não o consideraram, na função que exerceram, quanto por partícipes que consideraram que foram ensinados por alguém no Curso.

d) Para você, quem aprende no Curso? Essa questão foi respondida pelos mesmos partícipes da pesquisa que responderam a relativa ao item "b".

Em ambos instrumentos de pesquisa, essas questões foram respondidas de forma individual e em momentos distintos. Os sujeitos partícipes da pesquisa, respectivos ao sétimo semestre letivo do Curso, foram orientados a responderem a essas questões, como também as demais da pesquisa, tendo em vista toda a sua trajetória e o trabalho que desenvolviam e/ou desenvolveram no Curso e, especialmente no momento da entrevista, procurassem exemplificar as suas respostas considerando situações vivenciadas no Curso. Foram, ao total, 81 os registros de envio de questionários completos ao LimeSurvey efetuado por 56 alunos (isto é, 69,14\% dos sujeitos respondentes), 13 tutores $(16,05 \%)$ ), 10 professores (12,35\%), 4 coordenadores (4,94\%). Desse total, foram $52(64,20 \%)$ as respostas de partícipes da pesquisa que consideraram que o ensinar estava incluído entre as ações que realizaram no Curso e $29(35,80 \%)$ as daqueles que não o consideraram, sendo que estes últimos foram em sua totalidade alunos do Curso. Participaram da entrevista 13 alunos, 4 tutores, 4 professores e 1 coordenador, totalizando 22 sujeitos. Os dados coletados foram submetidos à análise de conteúdo (Moraes, 2003a, 2003b, 1999).

Tomou-se como base teórica para a análise dos dados emergentes da pesquisa relativos às quatro categorias mencionadas problematizações sobre a aprendizagem e 0 ensino consideradas por Piaget (1970, p. 71-86; 1974, p. 9-58) e o conjunto da obra piagetina, bem como as relações entre modelos epistemológicos e modelos pedagógicos propostas por Becker (2001, p. 19-30), entre outros referenciais teóricos que fundamentaram a Tese (Gelatti, 2012, p. 294-302). Os modelos epistemológicos empirista, apriorista e interacionista e, respectivamente, seus correspondentes modelos pedagógicos diretivo, não-diretivo e relacional, cada qual com um determinado modelo de sujeitos implicados nos processos de ensino e de aprendizagem, formaram um corpo teóricometodológico norteador da pesquisa. Enquanto um dos modos de praticar a Educação, a Educação a Distância compreende sujeitos que se articulam e estão envolvidos de variadas e distintas formas com o ensinar e o aprender, consoante os seus respectivos modelos epistemológicos e pedagógicos, tais como os mencionados. A identificação desses sujeitos por integrantes do Curso investigado é o objetivo deste artigo. 


\section{A QUEM SE ENSINA NO CURSO}

O ensinar envolve alguém a quem se ensina. Partindo da premissa de que se alguém ensina, ensina a alguém, quanto a quem os alunos, professores, tutores e coordenadores consideraram que ensinam no Curso, eles indicaram, principalmente, em ordem de relevância, os alunos, os tutores da sede, os professores de interdisciplina ${ }^{5}$ e os tutores do polo, como se apresenta abaixo, na Tabela $1^{6}$.

Tabela 1 - A quem os partícipes consideraram que ensinam no curso

\begin{tabular}{|c|l|c|c|}
\hline \multicolumn{1}{|c|}{$\begin{array}{c}\text { Questão 1: } \\
\text { A quem você ensina no Curso? }\end{array}$} & Contagem & Porcentagem \\
\hline $\mathbf{1}$ & \multicolumn{1}{|c|}{ aos alunos } & 36 & $44,44 \%$ \\
\hline $\mathbf{2}$ & aos tutores da sede & 12 & $14,81 \%$ \\
\hline $\mathbf{3}$ & aos tutores de polo & 10 & $12,35 \%$ \\
\hline $\mathbf{4}$ & $\begin{array}{l}\text { aos professores de interdisciplina } \\
\text { (incluindo os do seminário integrador) }\end{array}$ & 11 & $13,58 \%$ \\
\hline $\mathbf{5}$ & aos coordenadores de polo & 7 & $8,64 \%$ \\
\hline $\mathbf{6}$ & aos coordenadores de interdisciplina & 5 & $6,17 \%$ \\
\hline $\mathbf{7}$ & aos coordenadores gerais do Curso & 5 & $6,17 \%$ \\
\hline $\mathbf{8}$ & aos gerentes (ou coordenadores) no polo & 3 & $3,70 \%$ \\
\hline $\mathbf{9}$ & aos técnicos de suporte da área tecnológica & 2 & $2,47 \%$ \\
\hline $\mathbf{1 0}$ & $\begin{array}{l}\text { aos técnico-administrativos } \\
\text { (incluindo os da secretaria do Curso) }\end{array}$ & 2 & $2,47 \%$ \\
\hline $\mathbf{1 1}$ & Outros & 11 & $13,58 \%$ \\
\hline
\end{tabular}

Analisando os dados de acordo com a função dos integrantes do Curso, pode-se afirmar que um maior número de alunos, considerando a quem ensinam no Curso, assim indicou, em ordem de relevância: aos alunos (assim o responderam 12 alunos, correspondentes a 21,43\% dos alunos respondentes), enquanto colegas no Curso. Poucos alunos disseram que ensinam aos professores de interdisciplina, incluindo os do seminário integrador $^{7}$ (4 alunos: 7,14\%), aos tutores da sede (3 alunos: 5,36\%), aos tutores de polo (2 alunos: 3,57\%), aos coordenadores de polo (2 alunos: 3,57\%), aos coordenadores de interdisciplina (1 aluno: 1,79\%), aos coordenadores gerais do Curso (1 aluno: 1,79\%), aos gerentes ou coordenadores no polo (1 aluno: 1,79\%) e aos técnicos de suporte da área tecnológica (1 aluno: 1,79\%). Os alunos não consideraram que ensinam aos técnicoadministrativos, incluindo os da secretaria do Curso.

A respeito da presente questão, ao comentar a sua resposta, um aluno (A61-5) ponderou que ensina a todos os envolvidos no Curso, embora tenha considerado que não ensina aos técnico-administrativos. Outro aluno (A77-5) destacou que ensina a si próprio. Alguns alunos (A102-5, A103-5, A134-5) frisaram que ensinam a seus colegas, assim como outro aluno (A77-8) salientou: "Não ensino, mas oriento aos colegas quando estes tem dúvidas”. Por outro lado, um aluno (A48-5) afirmou que não ensina a ninguém do Curso. Corroborando o depoimento deste aluno (A48-5), outro aluno (A143-2) considerou 
que o ensinar não está incluído entre as suas ações no Curso, assim como uma aluna (A1905) afirmou: "não ensino no Curso, sou aluna”, argumentando que por ser aluna no Curso não pode ensinar. Outro, respondeu que é aluno do Curso (A85-5), como se justificasse que não lhe cabe a pergunta porque um aluno não ensinaria. Além dos já citados alunos (A48-5, A85-5, A190-5), cinco alunos (A-187-3, A11-1, A129-1, A154-1 e A162-1) salientaram que sua função no Curso é a de serem alunos e que, portanto, não ensinam. A necessidade de reforçarem que são alunos no contexto em que se apresentam as afirmativas e argumentações evidencia que esses alunos não se identificaram como sujeitos que ensinam no Curso. Esses depoimentos, considerando o conjunto das contribuições desses sujeitos à pesquisa, apontam para o questionamento de qual concepção de ensinar e, ainda, modelo pedagógico, esses sujeitos estão tomando como norteadores de sua prática educacional.

Como visto, pelo menos em uma parte considerável, esses alunos ponderaram que ser aluno e ensinar sejam elementos incompatíveis. A frequência sobressaliente desse posicionamento em contribuições de alunos à pesquisa é um tanto chamativa, pois, considerando também depoimentos desses alunos em entrevistas, é muito provável que eles estejam concebendo a sua atuação no Curso como sujeitos não ensinantes por acreditarem que o ensinar seja uma ação exclusiva do docente ou, ainda, própria de ser professor, pressuposto esse característico de um modelo pedagógico diretivo e de seu correspondente modelo epistemológico empirista (Becker, 2001, p. 15-19). O fato de alguns alunos afirmarem que quando ensinam o fazem enquanto são professores e atuantes em suas instituições educacionais, o que será visto a seguir, valida ainda mais essa argumentação.

Alguns alunos afirmaram que ensinam aos seus alunos em sala de aula (A22-5, A102-5, A190-5), quando estão atuando como professores em instituições educacionais durante a realização do estágio supervisionado do Curso. Um aluno (A27-3) observou que a etapa de realização de seu estágio, no qual atuou como professor, também fez parte de seu ensinar. Outros dois alunos (T-176-8 e A190-7) responderam que não ensinam no Curso, mas sim aos seus alunos, quando atuam como professores nas instituições educacionais nas quais trabalham. Percebe-se, assim, por parte de alguns alunos do Curso, o entendimento de que "aluno não ensina" e que a ação de ensinar apenas pode ser exercida quando este sujeito ocupa a função de professor. Outrossim, o ensinar pode estar sendo concebido por esses alunos apenas em seu sentido amplo, como trabalho, ocupação ou ofício, e não em seu sentido estrito, como ato de ensinar (Gelatti, 2012, p. 94-95) e, por isso, somente quem tem a função de ensinar é quem ensina no Curso.

Outras referências em relação à quem os partícipes consideraram que ensinam e à extensão das ações de ensinar aos alunos dos alunos do Curso, pôde ser visualizada em registros dos partícipes da pesquisa no ambiente virtual ROODA, principalmente em fóruns (ferramentas assíncronas) das interdisciplinas do Eixo Articulador 7, tal como nas seguintes mensagens enviadas por alunos do Curso em um fórum: “[...] Com o PA (Projeto de Aprendizagem) a aprendizagem está realmente sendo muito gratificante, pois estamos aprendendo juntos, como alunos e assim poderemos realizar o que aprendemos com nossos alunos” (A198) e “[...] esta proposta pedagógica pela qual eu particularmente me apaixonei chegou aos meus alunos junto com a minha empolgação pelas tecnologias [...]” (A102). Embora em ambientes virtuais do Curso, especialmente em ambientes das interdisciplinas no ROODA, foi possível visualizar situações nas quais alunos estão ensinando, particularmente a colegas (isto é, outros alunos do Curso) e a tutores e em fóruns das interdisciplinas, houve uma certa resistência por parte de alguns alunos em afirmar que 
ensinam no Curso, como se pôde observar em seus depoimentos, principalmente por conceberem a atividade de ensinar como uma atividade particular do docente.

A partir desses depoimentos, ressalta-se que o Curso PEAD partiu do propósito de graduar profissionais da educação em serviço, em especial professores não habilitados em nível superior, os quais em sua maioria atuam em escolas públicas estaduais e municipais. A proposta metodológica do Curso preocupou-se em articular as interdisciplinas com a prática pedagógica realizada nas escolas em que os alunos desenvolvem a docência (Carvalho et al., 2006, p. 21). Dessa forma, faz todo sentido que os alunos, quando questionados sobre o seu ensinar no Curso, tenham estabelecido uma relação direta da sua prática no Curso com o seu ensinar nas instituições educacionais nas quais atuam profissionalmente e/ou durante o estágio supervisionado, pois o próprio Curso apresentou em sua proposta pedagógica o objetivo de articular essa aproximação entre universidade e escola. Esse foi um dos dados que emergiu da pesquisa: do ponto de vista dos alunos, o ensinar no Curso se estende e, ainda, repercute, em seu ensinar na escola.

Todos os tutores afirmaram que ensinam aos alunos no Curso (assim o responderam 13 tutores, correspondentes a 100\% dos tutores respondentes). Poucos deles consideraram que ensinam aos professores de interdisciplina, incluindo os do seminário integrador (2 tutores: 15,38\%), aos tutores da sede (1 tutor: 7,69\%), aos tutores de polo (1 tutor: 7,69\%), aos coordenadores de polo (1 tutor: 7,69\%), aos coordenadores de interdisciplina (1 tutor: 7,69\%), aos coordenadores gerais do Curso (1 tutor: 7,69\%). Nenhum deles afirmou que ensinou aos gerentes ou coordenadores no polo, aos técnicos de suporte da área tecnológica e aos técnico-administrativos, incluindo os da secretaria do Curso.

Todos os professores também disseram que ensinam aos alunos (assim o responderam 10 professores, correspondentes a 100\% dos professores respondentes). Alguns professores consideraram que ensinam aos tutores da sede (6 professores: 60\%), aos tutores de polo (5 professores: 50\%), aos professores de interdisciplina, incluindo os do seminário integrador (3 professores: 30\%), aos coordenadores de polo (3 professores: $30 \%)$. Poucos professores afirmaram que ensinam aos coordenadores de interdisciplina (2 professores: 20\%), aos coordenadores gerais do Curso (2 professores: $20 \%$ ) e aos gerentes ou coordenadores no polo (2 professores: 20\%). Nenhum professor considerou que ensinou aos técnicos de suporte da área tecnológica e aos técnico-administrativos, incluindo os da secretaria do Curso. Um professor, o único que comentou a sua resposta à questão, afirmou que ensina e aprende a todo o momento com os diferentes sujeitos do Curso (P325), o que é um exemplo do que a maioria dos partícipes da pesquisa consideraram a respeito, embora em distintos graus de intensidade, com algumas exceções já apresentadas em depoimentos de alunos, tutores e professores.

Todos os coordenadores também disseram que ensinam aos tutores da sede (assim o responderam 4 coordenadores, correspondentes a 100\% dos coordenadores respondentes) e aos alunos (3 coordenadores: 75\%). Eles também consideraram que ensinam aos tutores de polo (3 coordenadores: 75\%), aos professores de interdisciplina, incluindo os do seminário integrador (3 coordenadores: 75\%) e aos coordenadores de polo ( 2 coordenadores: 50\%). Poucos coordenadores afirmaram que ensinam aos coordenadores de interdisciplina (1 coordenador: 25\%), aos coordenadores gerais do Curso (1 coordenador: 25\%), aos gerentes ou coordenadores no polo (1 coordenador: 25\%), aos técnicos de suporte da área tecnológica (1 coordenador: 25\%), aos técnico-administrativos, incluindo os da secretaria do Curso (1 coordenador: 25\%). 
Portanto, todos os grupos de sujeitos por função que exerceram no Curso - a de alunos, tutores, professores e coordenadores - consideraram que se ensinou a todos esses grupos de sujeitos e a outros integrantes do Curso, não obstante se tenha ensinado mais intensamente a uns do que a outros. Tendo presente os depoimentos apresentados por partícipes da pesquisa, alguns alunos do Curso consideraram os seus alunos - aqueles dos locais nos quais realizam estágios acadêmicos, nos quais atuaram como professores, em muitos casos nas próprias instituições educacionais em que trabalhavam - como, de certa forma, "extensões" do ensinar do Curso. Esses alunos do Curso ponderaram que o seu ensinar no Curso também os abrange, dimensão esta não considerada por parte de tutores, professores e coordenadores do Curso em seus depoimentos. O que desponta através dos depoimentos desses alunos, considerando que o propósito do Curso foi formar professores, consiste na repercussão das ações de ensinar do Curso PEAD através das quais os seus alunos aprendem como ensinar e aplicam esse conhecimento em sua prática de ensinar enquanto atuam como professores. Em vista disso, algumas ações de ensinar do Curso se estenderam aos alunos dos alunos do Curso.

\section{QUEM É ENSINADO NO CURSO}

Ensinar implica alguém que é ensinado e intenciona que alguém seja ensinado. No que se refere a quem alunos, tutores, professores e coordenadores do Curso consideraram que seja ensinado por alguém no Curso, setenta e dois partícipes da pesquisa disseram que consideram que sejam ensinados, enquanto quatro responderam que não o consideram, conforme apresenta a Tabela 2. Desses quatro, três são alunos e um é professor do Curso.

Tabela 2 - Partícipes que consideraram que sejam ensinados no curso

\begin{tabular}{|l|l|c|c|}
\hline & \multicolumn{1}{|c|}{$\begin{array}{c}\text { Questão 2: Você considera que seja } \\
\text { ensinado por alguém no Curso? }\end{array}$} & Contagem & Porcentagem \\
\hline $\mathbf{1}$ & Sim & 72 & $88,89 \%$ \\
\hline $\mathbf{2}$ & Não & 4 & $4,94 \%$ \\
\hline $\mathbf{3}$ & Outros & 1 & $1,23 \%$ \\
\hline
\end{tabular}

Quarenta e nove alunos (correspondentes a 87,50\% dos alunos respondentes) partícipes da pesquisa consideraram que sejam ensinados no Curso; três (correspondentes a 5,36\% dos alunos respondentes), que não sejam ensinados. Por suas contribuições à pesquisa, é possível afirmar que esses três alunos consideraram que não se ensina no Curso e que, portanto, não podem afirmar que sejam ensinados. No entanto, isso não significa que considerem que não existam ações educacionais intencionais no Curso. Segundo o que os seus depoimentos indicam, eles não consideraram que essas ações sejam identificadas ou nomeadas como "ensinar", em função de determinadas concepções epistemológicoeducacionais embutidas na palavra. Por um lado, a negação da ação de ensinar no Curso pode ser decorrente da crença destes alunos de serem “auto-suficientes” em relação aos processos de ensinar e de aprender, pressuposto esse característico de um modelo pedagógico não-diretivo, apoiado em um modelo epistemológico apriorista (Becker, 2001, p. 19-23). Por outro lado, em depoimentos de alunos, como também se percebe em depoimentos de tutores e até mesmo de professores, o ensinar é muitas vezes relacionado a 
um modelo pedagógico diretivo, fundamentado em um modelo epistemológico empirista e, por esse motivo, costuma ser compreendido de forma pedagógica negativa e contrária ao pressuposto de inovação pedagógica. Esta possui, por certo, estreita relação com o epistemológico (Leite et al., 2011, p. 33). Logo, esses alunos negaram que ensinam por compreender que o ensinar se opõe a concepções inovadoras de educação, as quais a maioria desses sujeitos do Curso atribuiu ao modelo pedagógico relacional, o qual tem como base epistemológica o modelo interacionista (p. 23-28).

Todos os doze tutores (correspondentes a 92,31\% dos tutores respondentes) disseram que são ensinados. Nove professores (correspondentes a $90 \%$ professores respondentes), sendo que dois deles também se identificaram como coordenadores, afirmaram que são ensinados no Curso, contudo um professor (P166-11) disse que não o é (correspondente a 10\% dos professores respondentes). Este professor afirmou que não é ensinado no Curso tanto na realização do questionário como em entrevista, ao passo que outro professor (P32-11) ressaltou que “constantemente” é ensinado no Curso. Todos os quatro coordenadores consideraram que são ensinados no Curso.

Sendo assim, todos os grupos de sujeitos por função que exerceram no Curso - a de alunos, tutores, professores e coordenadores - consideraram que todos esses grupos de sujeitos, como também outros integrantes do Curso, foram ensinados no Curso, apesar de que tenham sido ensinados mais veementemente por uns do que por outros. Partindo desse posicionamento, a seção seguinte tratará de quem os partícipes consideraram que lhes ensina no Curso.

\section{QUEM ENSINA NO CURSO}

Ensinar implica alguém que ensina ou, em outras palavras, um sujeito que exerce a ação de ensinar. No que se refere aos integrantes do Curso quem os partícipes da pesquisa consideraram que lhes ensina no mesmo, um maior número de partícipes disse que quem lhe ensina são, em ordem de relevância, os professores de interdisciplina, os tutores da sede, os tutores de polo e os alunos, conforme consta na sequência, na Tabela 3.

Tabela 3 - Quem os partícipes consideraram que lhes ensina no curso

\begin{tabular}{|c|l|c|c|}
\hline & \multicolumn{1}{|c|}{ Questão 3: Caso você considere que seja ensinado } \\
no Curso, quem lhe ensina? & Contagem & Porcentagem \\
\hline $\mathbf{1}$ & os alunos & 47 & $58,02 \%$ \\
\hline $\mathbf{2}$ & os tutores da sede & 59 & $72,84 \%$ \\
\hline $\mathbf{3}$ & os tutores de polo & 54 & $66,67 \%$ \\
\hline $\mathbf{4}$ & $\begin{array}{l}\text { os professores de interdisciplina } \\
\text { (incluindo os do seminário integrador) }\end{array}$ & 66 & $81,48 \%$ \\
\hline $\mathbf{5}$ & os coordenadores de polo & 32 & $39,51 \%$ \\
\hline $\mathbf{6}$ & os coordenadores de interdisciplina & 38 & $46,91 \%$ \\
\hline $\mathbf{7}$ & os coordenadores gerais do Curso & 32 & $39,51 \%$ \\
\hline $\mathbf{8}$ & os gerentes (ou coordenadores) no polo & 14 & $17,28 \%$ \\
\hline $\mathbf{9}$ & os técnicos de suporte da área tecnológica & 27 & $33,33 \%$ \\
\hline $\mathbf{1 0}$ & $\begin{array}{l}\text { os técnico-administrativos } \\
\text { (incluindo os da secretaria do Curso) }\end{array}$ & 12 & $14,81 \%$ \\
\hline $\mathbf{1 1}$ & Outros & 5 & $6,17 \%$ \\
\hline
\end{tabular}


Analisando os dados de acordo com a função dos integrantes do Curso, pode-se afirmar que os alunos ponderaram que quem lhes ensina no Curso são, em ordem de relevância: os professores de interdisciplina, incluindo os do seminário integrador (assim o responderam 47 alunos, correspondentes a 83,93\% dos alunos respondentes), os tutores da sede (42 alunos: 75\%), os tutores de polo (37 alunos: 66,07\%), os alunos (28 alunos: 50\%), os coordenadores de interdisciplina (13 alunos: 41,07\%), os coordenadores de polo (20 alunos: 35,71\%), os técnicos de suporte da área tecnológica (15 alunos: 26,79\%), os gerentes ou coordenadores no polo (10 alunos: 17,86\%). Poucos alunos (5 alunos: 8,93\%) disseram que os técnico-administrativos, incluindo os da secretaria do Curso, lhes ensinam no Curso. Em seu depoimento, um dos alunos (P32-11.1) acrescentou que quem lhe ensina são os alunos, os colegas e as equipes diretivas das instituições educacionais dos seus alunos. Outro aluno (A61-11.1) disse que "todos" lhe ensinam, fazendo referência às alternativas de resposta à questão.

Os tutores afirmaram que, entre os integrantes do Curso que lhes ensinam, estão os professores de interdisciplina, incluindo os do seminário integrador (assim o responderam 10 tutores, correspondentes a 76,92\% dos tutores respondentes), os alunos (9 tutores: 69,23\%), os tutores da sede (8 tutores: 61,54\%), os tutores de polo (8 tutores: 61,54\%), os coordenadores de interdisciplina (7 tutores: 53,85\%), os coordenadores de polo (6 tutores: 46,15\%), os coordenadores geral do Curso (6 tutores: 46,15\%), os técnicos de suporte da área tecnológica (6 tutores: 46,15\%). Poucos tutores consideraram que quem lhes ensina são os gerentes ou coordenadores no polo (1 tutor: 7,69\%) e os técnico-administrativos, incluindo os da secretaria do Curso (2 tutores: 15,38\%). Um tutor (T176-11.1) salientou que "cada participante do curso ensina algo, cada qual com suas dimensões de saber”. As “dimensões de saber” referidas pelo tutor podem se tratar tanto da área de formação acadêmica ou de ocupação profissional como dos campos conhecimento de domínio de cada um deles, os quais não necessariamente se restringem aos conhecimentos legitimados pelas instituições nas quais se formam ou trabalham (Sacristán, Gómez, 1998, p. 160). Portanto, além das ações de ensinar dos integrantes do Curso serem definidas pela função ou funções que eles exerceram no mesmo, segundo afirmaram alguns dos partícipes da pesquisa, questão essa tratada em seção anterior, de acordo com esse tutor (T176) essas ações também podem ser definidas por suas "dimensões de saber".

Os professores disseram que quem lhes ensina são os alunos (assim o responderam 8 professores, correspondentes a $80 \%$ dos professores respondentes), os professores de interdisciplina, incluindo os do seminário integrador (8 professores: 80\%), os tutores da sede (7 professores: $70 \%$ ), os tutores de polo (7 professores: $70 \%$ ), os coordenadores de interdisciplina (7 professores: 70\%), os coordenadores gerais do Curso (7 professores: 70\%), os coordenadores de polo (5 professores: 50\%), os técnicos de suporte da área tecnológica (4 professores: 40\%). Poucos professores consideraram que os técnicoadministrativos, incluindo os da secretaria do Curso (3 professores: 30\%), os gerentes ou coordenadores no polo (3 professores: 30\%) lhes ensinam no Curso. Um professor (P.C133-11.1), que também atua como coordenador do Curso, afirmou que todos lhe ensinam algo e com todos também aprende algo.

Os coordenadores afirmaram que quem lhes ensina são os alunos (assim o responderam 4 coordenadores, correspondentes a 100\% dos coordenadores respondentes), os tutores da sede (4 coordenadores: $100 \%$ ), os tutores de polo (4 coordenadores: 100\%), os 
professores de interdisciplina, incluindo os do seminário integrador (3 coordenadores: 75\%), os coordenadores de interdisciplina (3 coordenadores: 75\%), os coordenadores gerais do Curso (3 coordenadores: 75\%), os técnicos de suporte da área tecnológica (3 coordenadores: $75 \%$ ), os técnico-administrativos, incluindo os da secretaria do Curso (3 coordenadores: 75\%), os coordenadores de polo (2 coordenadores: 50\%). Apenas um coordenador (correspondente a 25\% dos coordenadores respondentes) considerou que os gerentes ou coordenadores no polo lhe ensinam.

Como visto, todos os grupos de sujeitos por função que exerceram no Curso - a de alunos, tutores, professores e coordenadores - consideraram que foram ensinados no Curso por todos esses grupos de sujeitos, bem como por outros integrantes do Curso, ainda que o sejam mais intensamente por uns do que por outros. Alunos disseram que tutores lhes ensinam quase que em mesmo número dos que disseram que professores lhes ensinam. As respostas à questão por tutores, coordenadores e professores foi mais uniforme, isto é, praticamente em mesmo número eles afirmaram que todos os referidos grupos de sujeitos ensinam no Curso. Tutores afirmaram que professores e coordenadores lhes ensinam quase que em mesmo número dos que afirmaram que alunos e seus colegas tutores lhes ensinam. Professores e coordenadores consideraram que alunos e tutores lhes ensinam praticamente tanto quanto os que afirmaram que seus colegas professores e coordenadores lhes ensinam. Portanto, está implicada no Curso uma variedade de sujeitos na ação de ensinar, em contraposição ao entendimento de que seria uma prática exclusiva do professor.

\section{QUEM APRENDE NO CURSO}

O ensinar, enquanto prática na qual se intenciona que alguém aprenda, envolve um sujeito a qual a ação de ensinar é dirigida. A respeito de quem aprende no Curso, os alunos, professores, tutores e coordenadores do Curso consideraram, principalmente, que os que aprendem são, em ordem de relevância, os alunos, os tutores de polo, os professores de interdisciplina, os tutores da sede, como pode ser visualizado na sequência, na Tabela 4.

Tabela 4 - Quem os partícipes consideraram que aprende no curso

\begin{tabular}{|c|c|c|c|}
\hline & $\begin{array}{c}\text { Questão 4: } \\
\text { Para você, quem aprende no Curso? }\end{array}$ & Contagem & Porcentagem \\
\hline 1 & os alunos & 68 & $83,95 \%$ \\
\hline 2 & os tutores da sede & 61 & $75,31 \%$ \\
\hline 3 & os tutores de polo & 66 & $81,48 \%$ \\
\hline 4 & $\begin{array}{l}\text { os professores de interdisciplina } \\
\text { (incluindo os do seminário integrador) }\end{array}$ & 65 & $80,25 \%$ \\
\hline 5 & os coordenadores de polo & 51 & $62,96 \%$ \\
\hline 6 & os coordenadores de interdisciplina & 53 & $65,43 \%$ \\
\hline 7 & os coordenadores gerais do Curso & 49 & $60,49 \%$ \\
\hline 8 & os gerentes (ou coordenadores) no polo & 41 & $50,62 \%$ \\
\hline 9 & os técnicos de suporte da área tecnológica & 35 & $43,21 \%$ \\
\hline 10 & $\begin{array}{l}\text { os técnico-administrativos } \\
\text { (incluindo os da secretaria do Curso) }\end{array}$ & 32 & $39,51 \%$ \\
\hline 11 & Outros & 20 & $24,69 \%$ \\
\hline
\end{tabular}


Analisando os dados de acordo com a função dos integrantes do Curso, pode-se afirmar que os alunos consideraram que quem aprende no Curso são, em ordem de relevância: os alunos (assim o responderam 46 alunos, correspondentes a 82,14\% dos alunos respondentes), os tutores de polo (44 alunos: 78,57\%), os professores de interdisciplina, incluindo os do seminário integrador (43 alunos: 76,79\%), os tutores da sede (40 alunos: 71,43\%), os coordenadores de interdisciplina (33 alunos: 58,93\%), os coordenadores de polo (31 alunos: 55,36\%), os coordenadores gerais do Curso (30 alunos: $53,57 \%$ ), os gerentes ou coordenadores no polo (24 alunos: 42,86\%). Os alunos consideraram, em menor número, que os técnicos de suporte da área tecnológica (20 alunos: 35,71\%) e os técnico-administrativos, incluindo os da secretaria do Curso (18 alunos: 32,14\%) aprendem no Curso.

Um aluno (A77-12) afirmou que a todo instante se aprende no Curso, assim como outro aluno (A104-8) afirmou que acredita que se aprende e se ensina em tempo integral no Curso. Um aluno (A76-12) observou que aprendem "[...] tanto os que buscam ensinar como os que buscam o aprender”. Outro aluno (A162-5) ponderou que, enquanto estudante, aprende mais intensamente no Curso do que em outro espaço educacional. Já um aluno (A14-12) acrescentou à lista de alternativas apresentadas à questão que também aprende com “colegas das escolas” e "alunos da escola”. Salienta-se, novamente, que muitos dos alunos do Curso atuavam como professores em instituições educacionais concomitantemente com a realização do Curso e que, portanto, alguns deles consideraram que o seu aprender no Curso, tal como o seu ensinar, se estendeu aos seus alunos.

Um aluno (A154-11.1) ressaltou que se aprende no Curso através da interação entre professor, aluno, colegas, tutores e o meio. Segundo outros alunos partícipes da pesquisa, "um aprende e ensina com o outro" (A102-10), sendo que "a aprendizagem ocorre através da interação com o outro" (A83-10), ou seja, "a interação promove a aprendizagem” (A135-10). Nesse sentido, ensinar requer especialmente que interações ocorram entre quem ensina e a quem se ensina. Esses sujeitos, quem ensina e a quem se ensina, podem ser identificados como polos da interação. É a partir dessas interações que conhecimentos podem ser construídos. Essas interações ocorrem para que principalmente um dos polos dessa interação (ou seja, a quem se ensina) possa aprender o objeto a ser conhecido, o que não significa que outros sujeitos, inclusive quem ensina, não possam aprender por intermédio dessas interações. Logo, a educação, como processo relacional, implica a interação constante entre “agentes e actores” (Garcia Aretio et al., 2009, p. 85-86).

Os tutores disseram que quem aprende no Curso são os alunos (assim o responderam 11 tutores, correspondentes a 84,62\% dos tutores respondentes), os tutores da sede (11 tutores: 84,62\%), os tutores de polo (11 tutores: 84,62\%), os professores de interdisciplina, incluindo os do seminário integrador (11 tutores: 84,62\%), os coordenadores de polo (10 tutores: 76,92\%), os coordenadores de interdisciplina (9 tutores: 69,23\%), os coordenadores gerais do Curso (8 tutores: 61,54\%). Em menor número, eles consideraram que os gerentes ou coordenadores no polo (7 tutores: 53,85\%), os técnicos de suporte da área tecnológica (7 tutores: 53,85\%) e os técnico-administrativos, incluindo os da secretaria do Curso (7 tutores: 53,85\%) aprendem no Curso. Um tutor (T116-12) disse que "todos aprendem com todos". Entretanto, outro tutor (T147-12) destacou, dentro dessa questão, que aprende "quem estiver disponível para esse processo”, explicando que “[...] é 
possível estar envolvido, mas não necessariamente disponível para a troca”, pois a aprendizagem está sujeitada a processos sócio-cognitivos do sujeito (Piaget, Gréco, 1974).

Os professores consideraram em maior número que quem aprende no Curso são: os alunos (assim o responderam 9 professores, correspondentes a $90 \%$ dos professores respondentes), os tutores de polo (9 professores: $90 \%$ ), os professores de interdisciplina, incluindo os do seminário integrador (9 professores: 90\%), os coordenadores de interdisciplina (9 professores: $90 \%$ ), os coordenadores gerais do Curso (9 professores: $90 \%$ ), os tutores da sede (8 professores: $80 \%$ ), os coordenadores de polo (8 professores: 80\%), os gerentes ou coordenadores no polo (8 professores: 80\%). Em menor número, consideraram que também aprendem no Curso os técnicos de suporte da área tecnológica (6 professores: 60\%) e os técnico-administrativos, incluindo os da secretaria do Curso (6 professores: 60\%). Um professor (P32-12) acrescentou que também aprendem no Curso “os alunos dos nossos alunos e a escola deles como um todo”, sendo o único professor e partícipe da pesquisa, com exceção dos alunos, a se reportar aos alunos dos alunos do Curso como também aprendentes do Curso.

Para os quatro coordenadores (correspondentes a 100\% dos coordenadores respondentes), todos os grupos de sujeitos por função que exerceram no Curso listados nas alternativas de resposta à questão aprendem no Curso, com exceção de um coordenador que não considerou os técnico-administrativos, incluindo os da secretaria do Curso, como sujeitos que aprendem no Curso. Ademais, um coordenador (C132-12) acrescentou que alunos(as) de graduação e de pós-graduação da UFRGS estão pesquisando a proposta do Curso PEAD - como foi o caso da presente pesquisadora, autora deste artigo -, buscando assim dizer que eles também aprendem no Curso. Um coordenador (P.C133-12), também professor do Curso, disse que "todos aprendem desde que se impliquem em processos de aprendizagem”, o que corrobora o posicionamento do recém citado tutor (T147-12) de que é preciso que a quem se ensina esteja “disponível” para o aprender para que este possa ocorrer. A disposição para aprender por parte do aprendente é, dessa maneira, um dos fatores imprescindíveis no ensinar (Pozo, 2002, p. 58).

Portanto, um considerável número de partícipes da pesquisa (T9-12, A19-12, A3012, A55-12, A61-12, A76-12, A77-12, T81-12, T116-12, P.C133-12, A145-12, A154-12, A162-12, T176-12, A177-12, A187-12) salientou que todos os grupos de sujeitos aprendem no mesmo. Sendo assim, os partícipes da pesquisa consideraram que são muitos os integrantes do Curso que aprendem no mesmo. Um maior número de alunos afirmou que eles próprios são os que aprendem no Curso e, em similar número, que também os tutores e os professores aprendem. Os tutores afirmaram em maior número que os que aprendem no Curso são os alunos, professores e eles mesmos e, em considerável número, que também os coordenadores aprendem. Os professores afirmaram em maior número que os que aprendem no Curso são os alunos, tutores do polo e eles mesmos e, em considerável número, que também os tutores do polo e os coordenadores aprendem. Todos os coordenadores, distintamente dos alunos, tutores e professores, conforme a análise apresentada, ponderaram que todos os grupos de sujeitos por função que exerceram no Curso - a de alunos, tutores, professores e coordenadores - aprendem no mesmo.

Na medida em que existem diversos sujeitos envolvidos nos processos de ensinar e de aprender, não apenas houve uma variedade de integrantes do Curso que se identificaram como sujeitos que ensinam, mas também que consideraram que aprendem no Curso. Ainda 
que os alunos sejam o "público" central para o qual o fazer do Curso está essencialmente direcionado, consoante a sua proposta pedagógica (Bordas et al., 2005), o que é próprio de um curso dessa natureza, todos os grupos de sujeitos por função que exerceram no Curso ponderaram que todos os grupos de sujeitos aprendem e aprendem com todos, com mais ou menos veemência e regularidade, o que não depende propriamente da função que exerceram no Curso. Considerando essa coletividade de sujeitos ensinantes e aprendentes, as múltiplas relações estabelecidas entre eles e as estruturas organizacionais configuradas a partir dessas relações, tornam-se relevantes a formação pedagógica continuada dos profissionais implicados (Corrêa, Ribeiro, 2013, p. 321) e o trabalho educativo conjunto para o fomento e a qualificação dessas relações em prol do ensinar e do aprender.

\section{RESULTADOS E CONCLUSÕES}

Tendo em vista os resultados que emergiram da pesquisa a partir da análise dos dados da Tese, mais especificamente os relativos às quatro categorias apresentadas no presente artigo, resulta que houve uma variação e uma diferenciação significativa no como os sujeitos do Curso PEAD consideraram a quem ensinam, quem é ensinado, quem ensina e quem aprende no Curso. Em grande parte, alunos, tutores, professores e coordenadores do Curso se identificaram como sujeitos que ensinam, que ensinam a alguém do Curso, que são ensinados e que aprendem no Curso e, portanto, a ação de ensinar não é restrita a um determinado sujeito. São muitos os sujeitos envolvidos em sua ação, com maior ou menor intensidade e frequência, podendo o ensinar ser praticado por qualquer sujeito do Curso.

Dessa forma, uma parcela significativa dos partícipes da pesquisa contrapõe-se, em geral, aos pressupostos de que: I. somente o professor pode ensinar e somente ele é quem ensina; II. somente o aluno pode aprender e somente ele é quem aprende; III. somente o aluno é ensinado e somente se ensina ao aluno; IV. o aluno é ensinado somente pelo professor ou pela equipe docente (como por coordenadores e tutores); V. o professor ou a equipe docente somente ensina a alunos. Entretanto, também houve uma parcela significativa dos partícipes da pesquisa que afirmou esses pressupostos, considerando que os dados oportunizados pelas quatro categorias analíticas discriminadas neste artigo foram situados perante o conjunto dos dados analisados na Tese (Gelatti, 2012).

A afirmação ou a negação da ação de ensinar foi evidenciada entre as racionalidades que embasaram propostas e práticas pedagógicas dos sujeitos do Curso. Uma grande parte dos sujeitos do Curso afirmou que ensinaram e/ou foram ensinados e que, portanto, a ação de ensinar esteve compreendida entre as ações realizadas no Curso, enquanto outra parte deles, particularmente de alunos, negou que ensinou no Curso, apoiados em pressupostos mencionados acima, principalmente por se conceber que somente o professor é quem ensina. A negação da ação de ensinar esteve em conformidade, em especial, com os seguintes argumentos, no caso das quatro categorias analisadas: a) por se relacionar e restringir o ensinar a pressupostos próprios de um determinado modelo pedagógico e modelo epistemológico e b) por se conceber o ensinar apenas em seu sentido amplo, como trabalho, ocupação ou ofício, e não em seu sentido estrito, como ato de ensinar.

Para concluir, no que concerne às quatro categorias analisadas, estiveram presentes pressupostos característicos dos modelos pedagógicos diretivo, não-diretivo e relacional, os quais se alicerçam, respectivamente, em pressupostos dos modelos epistemológicos empirista, apriorista e interacionista. Logo, o ensinar não está compreendido em um 


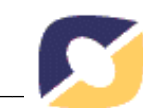

determinado modelo pedagógico e epistemológico, mas pode ser compreendido a partir de distintos modelos, como os tratados na pesquisa apresentada. Por consequência, a identificação dos sujeitos do ensinar dependerá de qual modelo pedagógico e epistemológico está sendo considerado no âmbito das concepções e práticas educacionais. 


\section{NOTAS DE TEXTO}

\footnotetext{
${ }^{1}$ Doutora em Educação pela Universidade Federal do Rio Grande do Sul - UFRGS. Foi professora do Curso de Licenciatura em Pedagogia a distância da UFRGS de 2006 a 2008, lecionando a disciplina "Fundamentos da Alfabetização" e três edições da disciplina "Escola, Projeto Pedagógico e Currículo".

${ }^{2}$ A pesquisa de Tese foi realizada com o apoio da CAPES, Coordenação de Aperfeiçoamento de Pessoal de Nível Superior - Brasil. Essa pesquisa foi orientada pelo Prof. Dr. Sérgio Roberto Kieling Franco da Universidade Federal do Rio Grande do Sul - UFRGS.

${ }^{3}$ LimeSurvey: é um softwtare de elaboração e aplicação de questionários ou formulários eletrônicos.

${ }^{4}$ ROODA, Rede Cooperativa de Aprendizagem: esse ambiente virtual está disponível no site institucional da UFRGS <https://ead.ufrgs.br/rooda/>.

${ }^{5}$ Interdisciplinas: "[...] estão contidas nos eixos articuladores e compreendem a abordagem de um tema amplo, que contém inúmeras possibilidades de enfoques temáticos e teórico-práticos”, consistindo em grandes áreas que agregam conhecimentos específicos e enfoques temáticos singulares na sua abordagem e transversais na Interdisciplina e no eixo (Bordas et al., 2005, p. 23-24).

${ }^{6}$ As tabelas de análise expostas ao longo deste artigo são compostas por quatro colunas. A segunda coluna apresenta as questões que possibilitaram dados mais específicos para a elaboração das quatro categorias analíticas, seguida de alternativas de resposta correspondentes a cada questão. As duas últimas colunas, identificadas como "contagem" e "porcentagem", apresentam, respectivamente, o número de partícipes que respondeu à questão e a sua porcentagem diante da totalidade de partícipes que a respondeu.

${ }^{7}$ Seminário Integrador: é oferecido em cada semestre letivo do Curso, sendo nele desenvolvidas “[...] oficinas tecnológicas e seminários envolvendo conteúdos e metodologias para integração dos conteúdos trabalhados em cada eixo", vislumbrando "[...] o trabalho teórico-prático em sala de aula, sua análise no portfólio educacional e o desenvolvimento de pesquisa cuja culminância dar-se-á no Trabalho de Conclusão do curso” (Bordas et al., 2005, p. 23).
}

\section{REFERÊNCIAS BIBLIOGRÁFICAS}

BECKER, Fernando. Educação e Construção do Conhecimento. Porto Alegre: Artmed, 2001.

BORDAS, Merion Campos; CARVALHO, Marie Jane Soares; NEVADO, Rosane Aragón. Projeto: Curso de Licenciatura em Pedagogia - Anos Iniciais do Ensino Fundamental. Universidade Federal do Rio Grande do Sul. Faculdade de Educação (FACED). Porto Alegre, 2005.

CARVALHO, Marie Jane Soares; NEVADO, Rosane Aragón; BORDAS, Merion Campos. Guia do Aluno. Curso de Licenciatura em Pedagogia a distância - Anos Iniciais do Ensino Fundamental. Faculdade de Educação (FACED). Porto Alegre, 2006.

CORRÊA, Guilherme Torres; RIBEIRO, Victoria Maria Brant. A formação pedagógica no ensino superior e o papel da pós-graduação stricto sensu. Educação e Pesquisa, São Paulo, v. 39, n. 2, p. 319-334, abr./jun. 2013.

GARCIA ARETIO, Lorenzo; CORBELLA, Marta Ruiz; BLANCO, Miriam García. Claves para la educación: actores, agentes y escenarios en la sociedad actual. Madrid: Narcea UNED, 2009. 
GELATTI, Lilian Schwab. Concepções e Práticas de Ensinar na Educação Superior a Distância. Porto Alegre, 2012. 315f. Tese (Doutorado em Educação) - Programa de Pós-Graduação em Educação, Faculdade de Educação, Universidade Federal do Rio Grande do Sul, Porto Alegre, 2012.

LEITE, Denise; GENRO, Maria Elly Herz; BRAGA, Ana Maria e Souza (Org.). Inovação e Pedagogia Universitária. Porto Alegre: Editora da UFRGS, 2011.

MORAES, Roque de. Uma Tempestade de Luz: a compreensão possibilitada pela análise textual discursiva. Porto Alegre: 2003a. (Mimeografado)

Análises Qualitativas: análise de conteúdo? análise de discurso? Porto Alegre: 2003b. (Mimeografado)

Análise de Conteúdo. Educação, Porto Alegre, ano XXII, n.37, p.7-32, mar. 1999.

PIAGET, Jean; GRÉCO, Pierre. Aprendizagem e Conhecimento. Rio de Janeiro: Freitas Bastos, 1974.

PIAGET, Jean. Psicologia e Pedagogia. Rio de Janeiro: Forense, 1970.

POZO, Juan Ignacio. Aprendizes e Mestres: a nova cultura da aprendizagem. Porto Alegre: ArtMed, 2002.

SACRISTÁN, J. Gimeno; GÓMEZ, A. I. Pérez. Compreender e Transformar o Ensino. 4.ed. Porto Alegre: ArtMed, 1998. 